ARTICLE

\title{
A platform for on-the-complex annulation reactions with transient aryne intermediates
}

\author{
Jason V. Chari (iD ${ }^{1,2}$, Katie A. Spence (iD) ${ }^{1,2}$, Robert B. Susick (iD ${ }^{1} \&$ Neil K. Garg (D) ${ }^{1 凶}$
}

Organometallic complexes are ubiquitous in chemistry and biology. Whereas their preparation has historically relied on ligand synthesis followed by coordination to metal centers, the ability to efficiently diversify their structures remains a synthetic challenge. A promising yet underdeveloped strategy involves the direct manipulation of ligands that are already bound to a metal center, also known as chemistry-on-the-complex. Herein, we introduce a versatile platform for on-the-complex annulation reactions using transient aryne intermediates. In one variant, organometallic complexes undergo transition metal-catalyzed annulations with in situ generated arynes to form up to six new carbon-carbon bonds. In the other variant, an organometallic complex bearing a free aryne is generated and intercepted in cycloaddition reactions to access unique scaffolds. Our studies, centered around privileged polypyridyl metal complexes, provide an effective strategy to annulate organometallic complexes and access complex metal-ligand scaffolds, while furthering the synthetic utility of strained intermediates in chemical synthesis.

\footnotetext{
${ }^{1}$ Department of Chemistry and Biochemistry, University of California, Los Angeles, CA, USA. ${ }^{2}$ These authors contributed equally: Jason V. Chari, Katie A. Spence. ${ }_{\text {email: neilgarg@chem.ucla.edu }}$
} 
O rganometallic complexes are prevalent in chemistry and biology, with applications ranging from usage as highly selective catalysts $^{1}$ to therapeutics ${ }^{2}$ and enzyme cofactors $^{3}$. Key to this versatility is the ability to tune function through manipulation of ligand structure. Fine tuning of the ligand sphere can lead to profound changes in the properties of an organometallic complex, including stereoelectronic and photophysical properties, catalyst turnover rate and stability ${ }^{4}$. Thus, the continued growth of organometallic chemistry is contingent on the capacity to access metal-ligand architectures with increased structural diversity and complexity.

Conventional synthetic approaches toward organometallic complexes involve reliance on ligand synthesis followed by coordination to a metal center (Fig. 1a). This general approach remains modular and adaptable, accounting for the syntheses of the majority of known metal-ligand complexes. Nonetheless, this general strategy can have drawbacks in the syntheses of notable ligand classes. For example, the synthesis of strongly chelating ligands can be challenging due to their propensity to form stable metal-ligand chelates and, in turn, prevent the use of metal-mediated transformations such as cross-couplings, $\mathrm{C}-\mathrm{H}$ functionalization, and annulation reactions ${ }^{5}$. In addition, highly rigid ligand systems can also have poor solubility in organic solvents, thus complicating their syntheses and subsequent coordination to metal centers ${ }^{6,7}$. Finally, ligand synthesis may require long, linear reaction sequences, which can render the process of synthesizing large libraries of organometallic derivatives cumbersome or impractical.

Divergent synthetic routes to organometallic complexes, analogous to those which have proven valuable in medicinal chemistry, are important for generating structurally diverse libraries of compounds. Toward this end, a nascent synthetic approach that complements traditional coordination chemistry is chemistry-onthe-complex ${ }^{8}$, whereby ligands are modified after being bound to a metal center. This strategy provides an attractive means for rapid structural diversification of metal-ligand complexes and can serve to circumvent the aforementioned challenges often encountered in ligand synthesis.

Chemistry-on-the-complex has proven effective in the synthesis of heterodimetallic complexes ${ }^{9}$, with applications in artificial photosynthesis ${ }^{10}$, along with the synthesis and elaboration of ferrocenyl $1^{11,12}$ and porphyrin ${ }^{13}$ structures. These studies demonstrate the value of on-the-complex approaches in diversityoriented synthesis, but also expose the need for further reaction development in this area. One illustrative example of chemistryon-the-complex is highlighted in Fig. 1b, where Davies and coworkers strategically utilized Suzuki-Miyaura cross-coupling reactions of pre-coordinated dimeric rhodium complexes toward the discovery of catalysts $\mathbf{1}$ used for the functionalization of unactivated $\mathrm{C}-\mathrm{H}$ bonds ${ }^{14}$. This case demonstrates the value of the general design, but also highlights that chemistry-on-thecomplex is most often used to introduce one bond relative to a given functional group. Methods that allow for the formation of more than one bond using chemistry-on-the-complex remain more limited. Examples include azide cycloadditions (click chemistry) and well-established condensation reactions, resulting in products such as $\mathbf{2}^{15}$ and $3^{16}$, respectively.

In considering the strategic generation of new ring systems onthe-complex, transient aryne intermediates provide a compelling entryway (Fig. 2). Although arynes and related species were once avoided due to their high reactivity, they have recently gained popularity in a number of applications as useful synthons for building molecular complexity $17-26$. For example, strained cyclic intermediates such as 4-7 (Fig. 2a) have been used to access heterocycles of value to medicinal chemistry ${ }^{27}$, widely used phosphine ligands ${ }^{28,29}$, agrochemicals ${ }^{30}$, and natural products ${ }^{31}$. Nonetheless, the usage of transient aryne intermediates in a

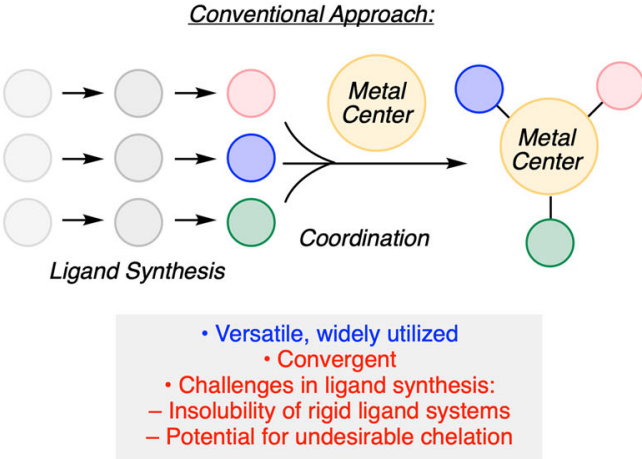

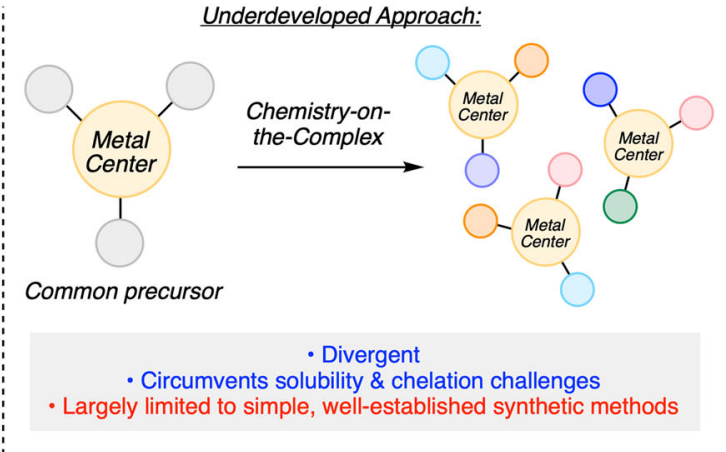

b Prior Studies: Chemistry-on-the-Complex
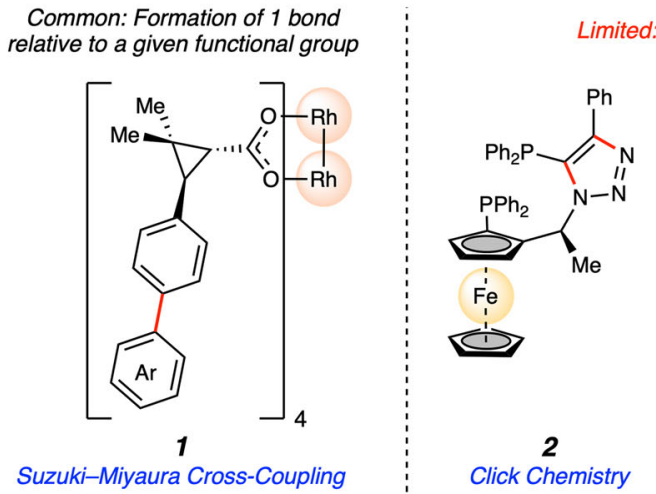

mited: Annulation reactions forming multiple bonds

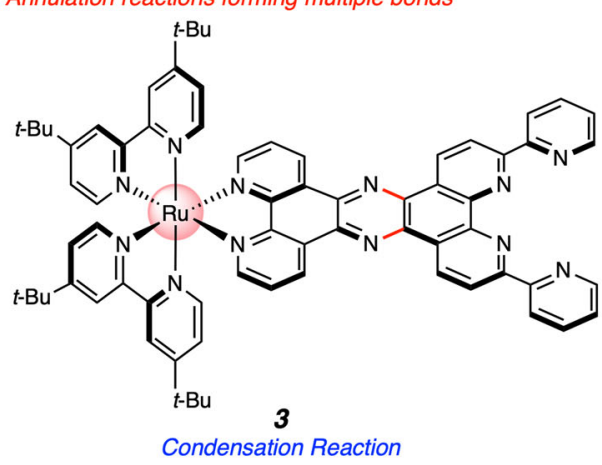

Fig. 1 General synthetic approaches toward metal-ligand complexes. a Comparison of coordination chemistry and chemistry-on-the-complex. $\mathbf{b}$ Prior studies involving chemistry-on-the-complex. Me, methyl; Ph, phenyl; $t$-Bu, tert-butyl. 
a In-Situ Generated Aryne and Cyclic Alkyne Intermediates as Valuable Synthons

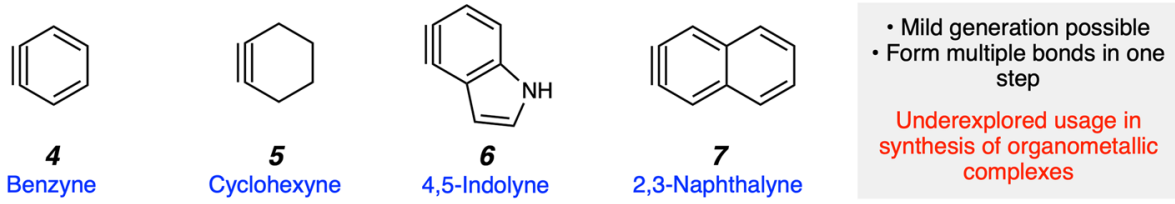

b This study: Platform for On-the-Complex Annulations using Arynes

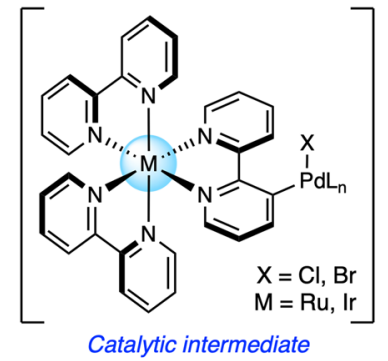

8

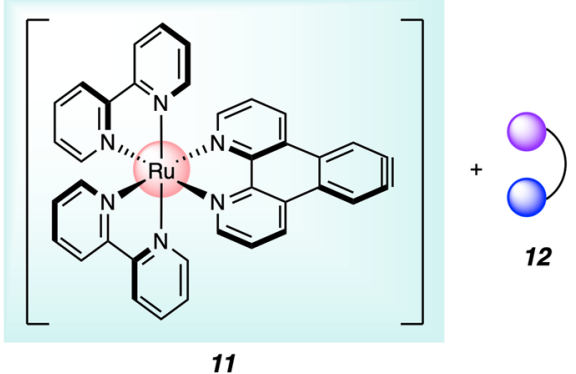

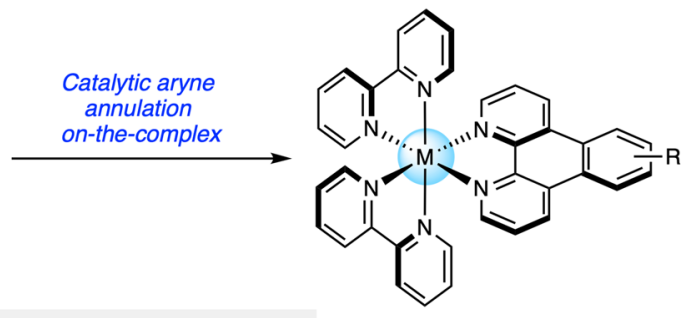

10

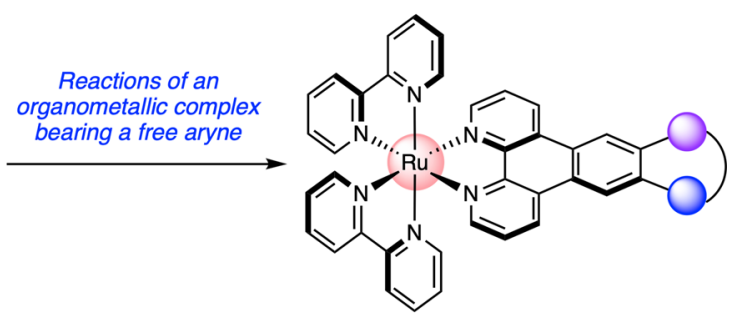

13

Fig. 2 Arynes-on-the-complex approach to metal complexes. a Aryne and cyclic alkyne intermediates. b Our approach to the direct manipulation of polypyridyl metal complexes using arynes.

chemistry-on-the-complex approaches has remained limited, with only two reports in the literature to date ${ }^{32,33}$. Both examples demonstrate the feasibility of aryne Diels-Alder trappings, but require that the organometallic complex bear a reactive diene ligand. A promising avenue for aryne chemistry-on-the-complex lies in the modification of polypyridyl metal complexes, whose applications span various chemical, biological, and therapeutic disciplines $^{34-43}$.

Herein, we show that intercepting arynes on-the-complex provides a versatile platform for the strategic manipulation of organometallic compounds (Fig. 2b). We disclose two variants. In the first, readily available aryl halides are embedded in the ligand framework and enable palladium-catalyzed annulations with in situ generated arynes. This proceeds via the reaction of catalytically generated bis(metallic) species $\mathbf{8}$ and fleeting aryne intermediates $\mathbf{9}$ to give annulated products $\mathbf{1 0}$. In the other variant, compound 11, a unique organometallic complex that bears an unligated aryne, is generated transiently. In situ trapping with cycloaddition partners 12 gives cycloadducts 13 . Our approaches enable the formation of multiple carbon-carbon $(\mathrm{C}-\mathrm{C})$ bonds in a single operation, offer a means to access functionalized polypyridyl metal complexes, underscore the utility of traditionally avoided aryne intermediates, and validate the aryne on-the-complex approach for accessing a diverse range of organometallic compounds.

\section{Results}

Development of the Pd-catalyzed on-the-complex aryne reaction. To initiate our studies, we sought to identify a versatile functional group handle for aryne on-the-complex manipulations. We settled on the use of aryl halides, given their ready availability and their prevalence in transition metal-catalyzed reactions, and prepared halogenated $\mathrm{Ru}\left(\right.$ bpy) ${ }_{3}$ derivatives 14 (Fig. 3 and see Supplementary Information). Although many impressive examples of Pd-catalyzed transformations of arynes have now been reported $^{44-51}$ use of this chemistry in the manipulation of organometallic complexes has remained unexplored. Inspired by Larock's impressive annulation of biaryl halides ${ }^{52,53}$, we sought to perform a Pd-catalyzed annulation of $\mathbf{1 4}$ with commercially available benzyne precursor 15. Initial attempts involved the use of Pd $(\mathrm{dba})_{2}$ and $\mathrm{P}(o \text {-tolyl })_{3}$, in the presence of $\mathrm{CsF}$, but were met with limited success, as we observed formation of the desired $\pi$-extended adduct 16, albeit in only $2 \%$ yield (entry 1 ). Instead, undesired protodehalogenation product, $\mathrm{Ru}(\mathrm{bpy})_{3}(\mathbf{1 7})$, was observed in $48 \%$ yield. Efforts to prevent this dehalogenation pathway via reduced temperatures and rigorous exclusion of air and moisture proved unfruitful ${ }^{54}$, as did the use of other $\mathrm{Pd}^{0}$ sources such as $\mathrm{Pd}\left(\mathrm{PPh}_{3}\right)_{4}$ (e.g., entry 2). Alternatively, the use of $\mathrm{Pd}(\mathrm{OAc})_{2}$ led to an improved $26 \%$ yield of the desired $\pi$-extended adduct 16 (entry 3 ). By increasing the catalyst and ligand loadings to $10 \mathrm{~mol} \%$, we observed a further increase in yield of $\mathbf{1 6}$ to $71 \%$, with a reaction time of just 30 min (entry 4). Employing modified ratios of the co-solvents, acetonitrile and toluene, resulted in decreased reaction efficiency (entries 5 and 6) (CsF, which governs aryne formation, has sparing solubility in organic solvents. By modulating the solvent mixture, one can tune the effective concentration of aryne in solution. In a catalytic reaction, such as that reported herein, it is critical to balance the amount of aryne in solution relative to the reactive organometallic species.). Finally, shifting from brominated substrate 14a to chlorinated derivative $\mathbf{1 4 b}$ effectively shut down the dehalogenation pathway and provided the desired product in $78 \%$ yield (entry 7). We surmise that the conversion of $\mathbf{1 4}+\mathbf{1 5}$ to $\mathbf{1 6}$ proceeds via initial oxidative addition and aryne formation occurring 


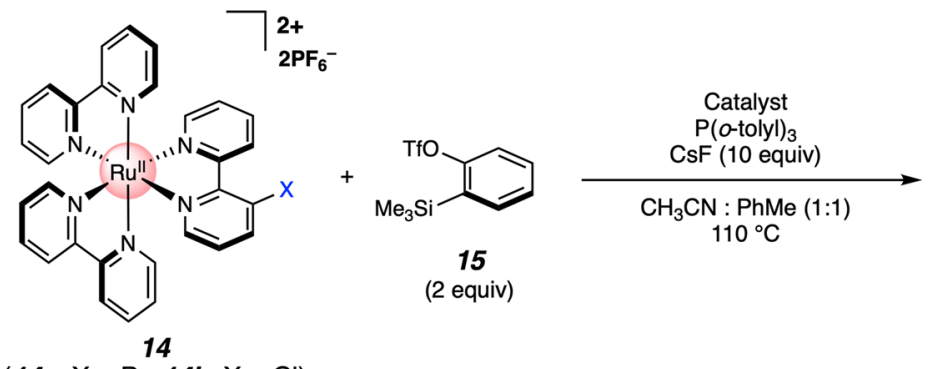

(14a: $\mathrm{X}=\mathrm{Br}, 14 b: \mathrm{X}=\mathrm{Cl})$

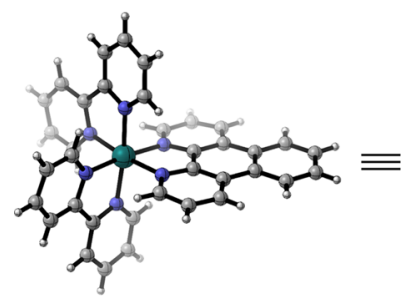

$[X-\text { ray }]^{a}$

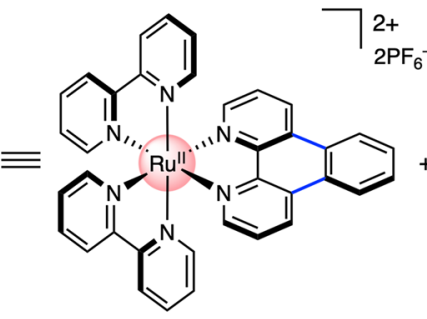

16

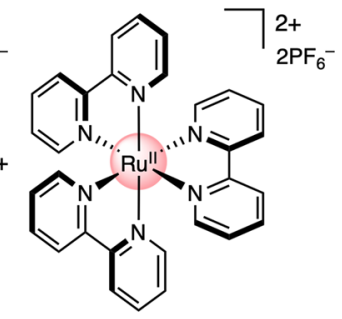

17

\begin{tabular}{ccccccccc}
\hline Entry & Catalyst & $X$ & $\begin{array}{c}\text { Catalyst } \\
\text { Loading }\end{array}$ & $\begin{array}{c}\text { Ligand } \\
\text { Loading }\end{array}$ & $\begin{array}{c}\mathrm{CH}_{3} \mathrm{CN}: \\
\mathrm{PhMe}\end{array}$ & Time & Yield of $\mathbf{1 6}^{b}$ & Yield of 17 $^{b}$ \\
\hline 1 & $\mathrm{Pd}(\mathrm{dba})_{2}$ & $\mathrm{Br}$ & $5 \mathrm{~mol} \%$ & $5 \mathrm{~mol} \%$ & $1: 1$ & $2 \mathrm{~h}$ & $2 \%$ & $48 \%$ \\
2 & $\mathrm{Pd}\left(\mathrm{PPh}_{3}\right)_{4}$ & $\mathrm{Br}$ & $5 \mathrm{~mol} \%$ & $5 \mathrm{~mol} \%$ & $1: 1$ & $2 \mathrm{~h}$ & $2 \%$ & $48 \%$ \\
3 & $\mathrm{Pd}(\mathrm{OAc})_{2}$ & $\mathrm{Br}$ & $5 \mathrm{~mol} \%$ & $5 \mathrm{~mol} \%$ & $1: 1$ & $2 \mathrm{~h}$ & $26 \%$ & $24 \%$ \\
\hline 4 & $\mathrm{Pd}(\mathrm{OAc})_{2}$ & $\mathrm{Br}$ & $10 \mathrm{~mol} \%$ & $10 \mathrm{~mol} \%$ & $1: 1$ & $30 \mathrm{~min}$ & $71 \%$ & $16 \%$ \\
\hline 5 & $\mathrm{Pd}(\mathrm{OAc})_{2}$ & $\mathrm{Br}$ & $10 \mathrm{~mol} \%$ & $10 \mathrm{~mol} \%$ & $3: 1$ & $30 \mathrm{~min}$ & $61 \%$ & $19 \%$ \\
6 & $\mathrm{Pd}(\mathrm{OAc})_{2}$ & $\mathrm{Br}$ & $10 \mathrm{~mol} \%$ & $10 \mathrm{~mol} \%$ & $1: 3$ & $30 \mathrm{~min}$ & $35 \%$ & $28 \%$ \\
\hline 7 & $\mathrm{Pd}(\mathrm{OAc})_{2}$ & $\mathrm{Cl}$ & $10 \mathrm{~mol} \%$ & $10 \mathrm{~mol} \%$ & $1: 1$ & $30 \mathrm{~min}$ & $78 \%$ & $0 \%$ \\
\hline
\end{tabular}

Fig. 3 Optimization studies for Pd-catalyzed annulation of benzyne onto Ru-polypyridyl complex $\mathbf{1 4}$. apF 6 counterions have been removed from the $X_{-}$ ray crystal structure for clarity. bYields were determined by ${ }^{1} \mathrm{H}$ NMR analysis, using 1,3,5-trimethoxybenzene as an external standard. OTf, trifluoromethanesulfonate.

concomitantly (see Figs. 2b, 8 and 9), followed by aryne insertion, palladation, and reductive elimination (For a pertinent report and proposed mechanism for Pd-catalyzed annulation of arynes with halobiaryl substrates, see ref. ${ }^{55}$.). It is worth noting that attempts to perform the analogous annulation on uncoordinated bromo- or chlorobipyridine ligands proved unproductive, potentially owing to $N, N$-chelation of palladium (see Supplementary Information), thus highlighting an aforementioned benefit of on-the-complex chemistry.

Scope of the Pd-catalyzed annulation. Variation of either the aryne or organometallic component was tolerated in the annulation, thus giving rise to a range of polypyridyl metal complexes in synthetically useful yields. With regard to the aryne component (Fig. 4), benzyne adduct $\mathbf{1 6}$ was isolated in $81 \%$ yield $(X=\mathrm{Cl})$ or $69 \%$ yield $(X=\mathrm{Br})$ using standard column chromatography. Notably, the only available protocol to access the diazatriphenylene ligand found in $\mathbf{1 6}$ involves the use of hazardous reagents and exceptionally forcing conditions ${ }^{56}$. N-Me-4,5-indolyne could also be employed to deliver adduct 21 in $80 \%$ yield ( $X$ $=\mathrm{Cl})$ or $75 \%$ yield $(X=\mathrm{Br})$, thus demonstrating the expedient incorporation of a heterocycle into the $\pi$-framework of the metal complex. Naphthalynes were also deemed competent reaction partners, as judged by the formation of $\mathbf{2 2}$ and 23. Prior routes to synthesize the naphthophenanthroline ligand present in $\mathbf{2 2}$ are lengthy or low yielding ${ }^{57}$, in part due to poor solubility of the free ligand ${ }^{6}$.

Although we primarily focused the current study on $\mathrm{Ru}$ complexes, we opted to probe the methodology in the context of Ir-centered polypyridyl complexes as well. Ir-centered polypyridyl complexes are prevalent in photochemistry ${ }^{58-61}$, with documented value of extended $\pi$-conjugation in structure-property relationship studies ${ }^{62}$. We were gratified to find that the methodology could be used to access several $\operatorname{Ir}(\mathrm{ppy})_{2}$ bpy derivatives, as delineated in Fig. 5. Via the intermediacy of benzyne and 2,3-naphthalyne, $\mathbf{2 6}$ and $\mathbf{2 7}$ could be accessed in $75 \%$ and $71 \%$ yield, respectively. Excellent yields were also observed upon varying the phenylpyridine ligands of the substrate, as isoquinolinyl annulation product $\mathbf{2 8}$ and tetrafluorinated adduct $\mathbf{2 9}$ could each be obtained in high yields from the corresponding chloride substrates.

To assess the possibility of carrying out multiple annulations on a given organometallic complex and test the limits of our aryne on-the-complex chemistry, we prepared Ru complexes $\mathbf{3 0}$ and 32, bearing two or three chlorides, respectively (Fig. 6). Subjecting these complexes independently to slightly modified reaction conditions delivered double and triple annulation products 31 and 33, via the efficient formation of four or six new $\mathrm{C}-\mathrm{C}$ bonds, respectively. Half of the bonds formed in either process arise from arene $\mathrm{C}-\mathrm{H}$ functionalization. 


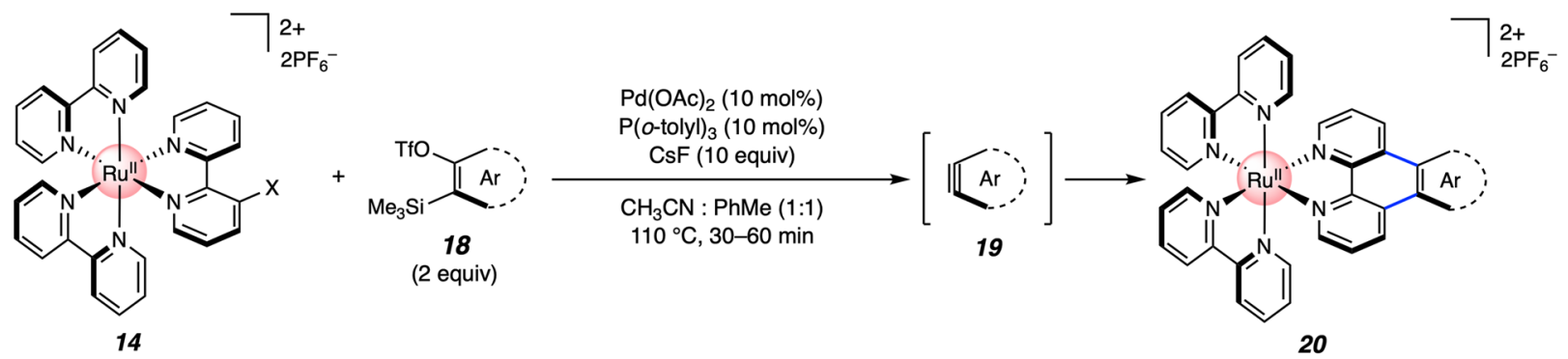

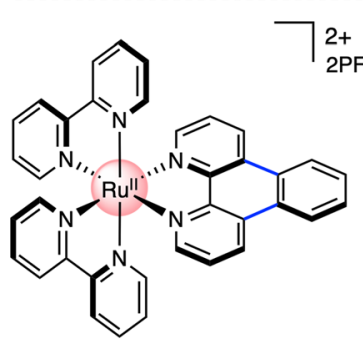

16

$(81 \%$ Yield, $\mathrm{X}=\mathrm{Cl})$ $(69 \%$ Yield, $\mathrm{X}=\mathrm{Br})$

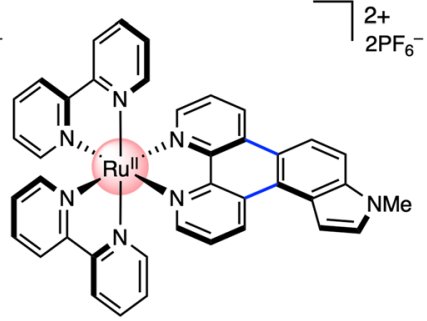

21

$(80 \%$ Yield, $\mathrm{X}=\mathrm{C})$

$(75 \%$ Yield, $X=B r)$

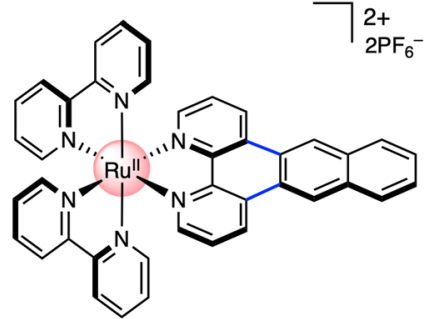

22

$(76 \%$ Yield, $\mathrm{X}=\mathrm{Cl})$ $(61 \%$ Yield, $X=B r)$

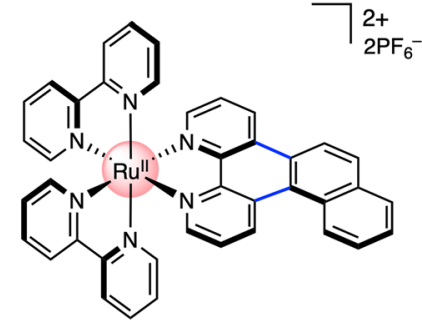

23

$(61 \% \text { Yield, } \mathrm{X}=\mathrm{Br})^{\mathrm{a}}$

Fig. 4 Aryne scope of the Pd-catalyzed aryne annulation. Yields shown reflect the average of two isolation experiments. ${ }^{a}$ Significant decomposition was observed when $X=\mathrm{Cl}$. Me, methyl; OTf, trifluoromethanesulfonate.

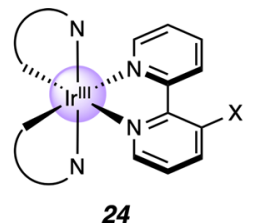

$(\mathrm{X}=\mathrm{Br}, \mathrm{Cl})$

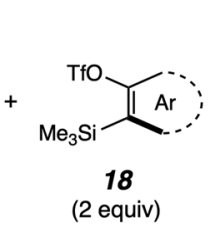

(2 equiv)

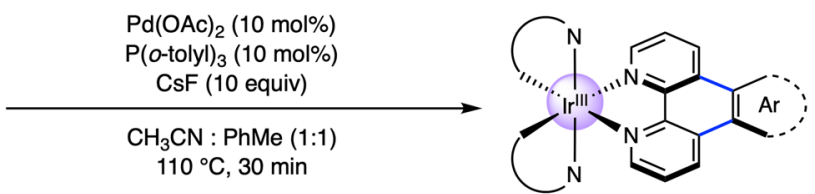

25

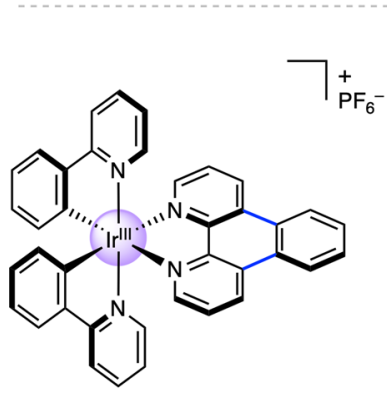

26

$(75 \%$ yield, $\mathrm{X}=\mathrm{Br})$

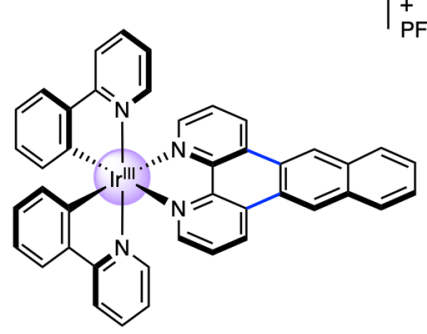

27

$(71 \%$ yield, $\mathrm{X}=\mathrm{Br})$

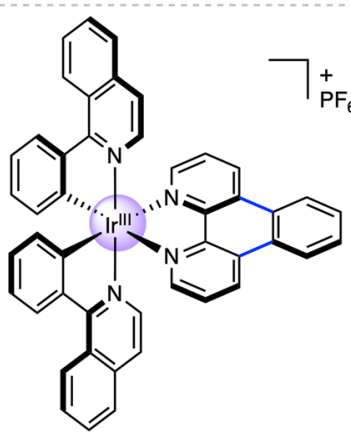

28

$(91 \%$ yield, $\mathrm{X}=\mathrm{Cl})$

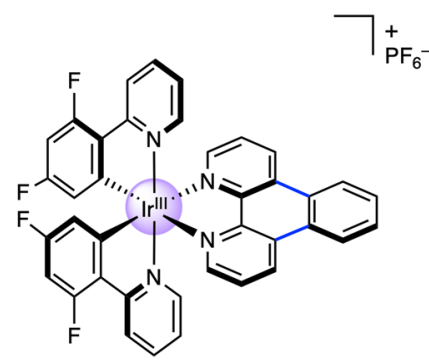

29

$(91 \%$ yield, $\mathrm{X}=\mathrm{Cl})$

Fig. 5 Pd-catalyzed aryne annulation of Ir-centered polypyridyl metal complexes. Yields shown reflect the average of two isolation experiments. OTf, trifluoromethanesulfonate.

Generation and trapping of an organometallic aryne. With an aryne-driven method for the annulation of organometallic complexes in hand, we sought to exploit this methodology to further extend the utility of aryne chemistry in accessing organometallic complexes. In particular, we sought to generate a free aryne on the organometallic complex itself and trap it in cycloaddition reactions. In contrast to arynes coordinated directly to metal centers (e.g., $\mathrm{Zr}, \mathrm{Ti})^{55}$, which are well-studied, free arynes embedded in an organometallic framework have remained elusive. Notably, previous efforts toward organometallic species bearing a free aryne have been met with difficulty ${ }^{63}$, and we therefore viewed the development of strategies in this area as an opportunity for advances in both aryne chemistry and chemistryon-the-complex. As shown in Fig. 7, we targeted silyl triflate 35 as the suitable aryne precursor. Unfortunately, initial efforts to access 35 via the annulation of Ru-complex $14 \mathrm{~b}$ with bis(silyl triflate) $34^{64}$ proved unsuccessful. As a workaround, we employed methoxymethyl (MOM) ether 36, prepared in two steps from commercially available materials, in the annulation reaction. After careful tuning of reaction conditions, adduct 37 could be generated in $80 \%$ yield with retention of both the MOM ether and trimethylsilyl group ${ }^{65}$. Subsequent cleavage of the MOM group, followed by triflation, delivered the desired silyl triflate 35 in $73 \%$ yield over two steps. 


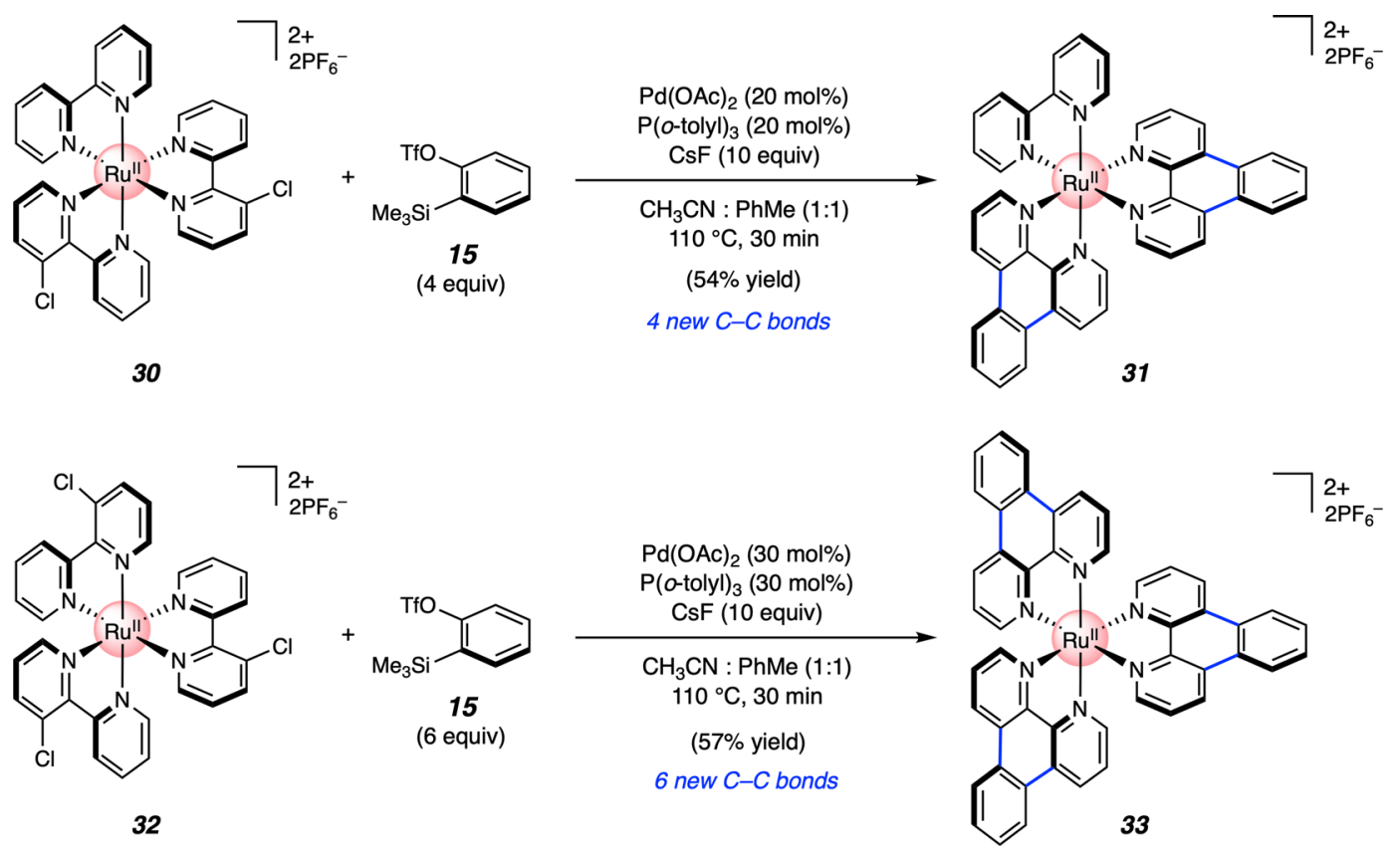

Fig. 6 Pd-catalyzed aryne annulation at multiple sites of Ru complexes. Yields shown reflect the average of two isolation experiments. OTf, trifluoromethanesulfonate.

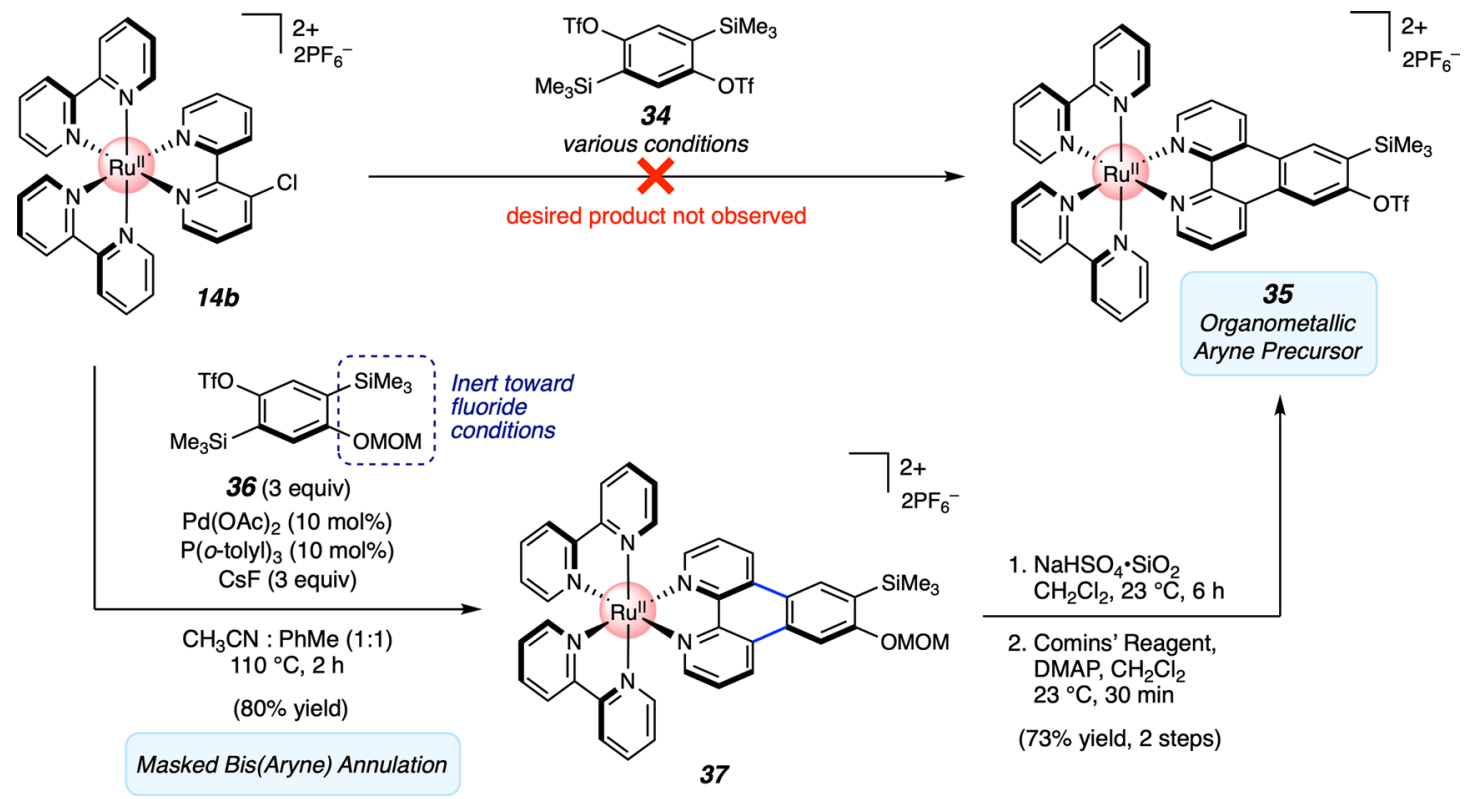

Fig. 7 Synthesis of an organometallic aryne precursor via masked bis(aryne) annulation. OTf, trifluoromethanesulfonate; MOM, methoxymethyl; DMAP, 4-dimethylaminopyridine.

As highlighted in Fig. 8a, we found that silyl triflate 35 indeed served as a suitable precursor to aryne 11, which, in turn, underwent cycloaddition in situ with trapping partners 12 . Trapping of $\mathbf{1 1}$ in the presence of 2,5-dimethylfuran (38) gave Diels-Alder adduct 41 in 50\% yield. In addition, a formal [2+2] cycloaddition of 11 with diketene acetal 39 was achieved, generating adduct $\mathbf{4 2}$ bearing a carbonyl functional handle. Finally, trapping of 11 with tetraphenylcyclopentadienone (40) gave rise to the unusual adduct $\mathbf{4 3}$ via a Diels-Alder and subsequent cheletropic cycloreversion to extrude CO. Complex 43 displays an excited state lifetime that is roughly two-fold longer than that of $\mathrm{Ru}(\mathrm{bpy})_{3}$ (see Supplementary Information).
Overall, the ability to access 41-43 from aryne precursor 35 showcases a free aryne being generated directly on an organometallic complex and demonstrates the utility of such species to access metal complexes with a diverse array of ring systems. Moreover, the results shown in Figs. 7 and 8a provide an unconventional strategy to access unique coordination complexes via two iterations of aryne on-the-complex chemistry (i.e., $\mathbf{1 4 b} \rightarrow$ 37 and $35 \rightarrow 41-43$ ), which collectively enables the formation of four $\mathrm{C}-\mathrm{C}$ bonds in each organometallic complex made.

Lastly, we explored the possibility of further manipulating the interesting organometallic complex 43 . Geometry optimization of 43 via DFT calculations suggests that its four phenyl substituents 


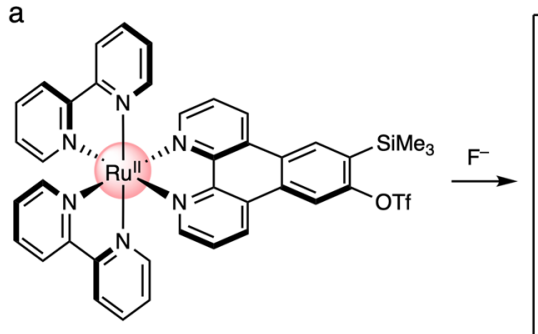

35

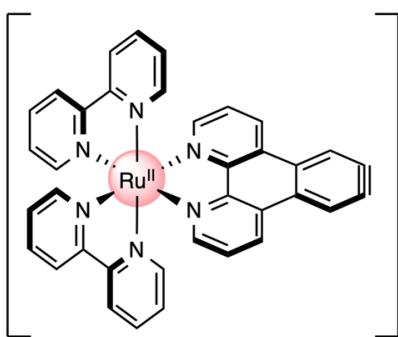

11

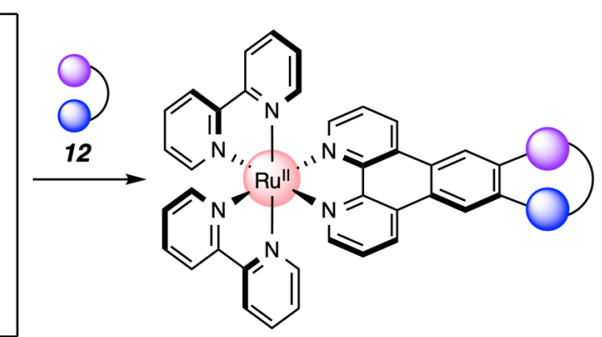

13

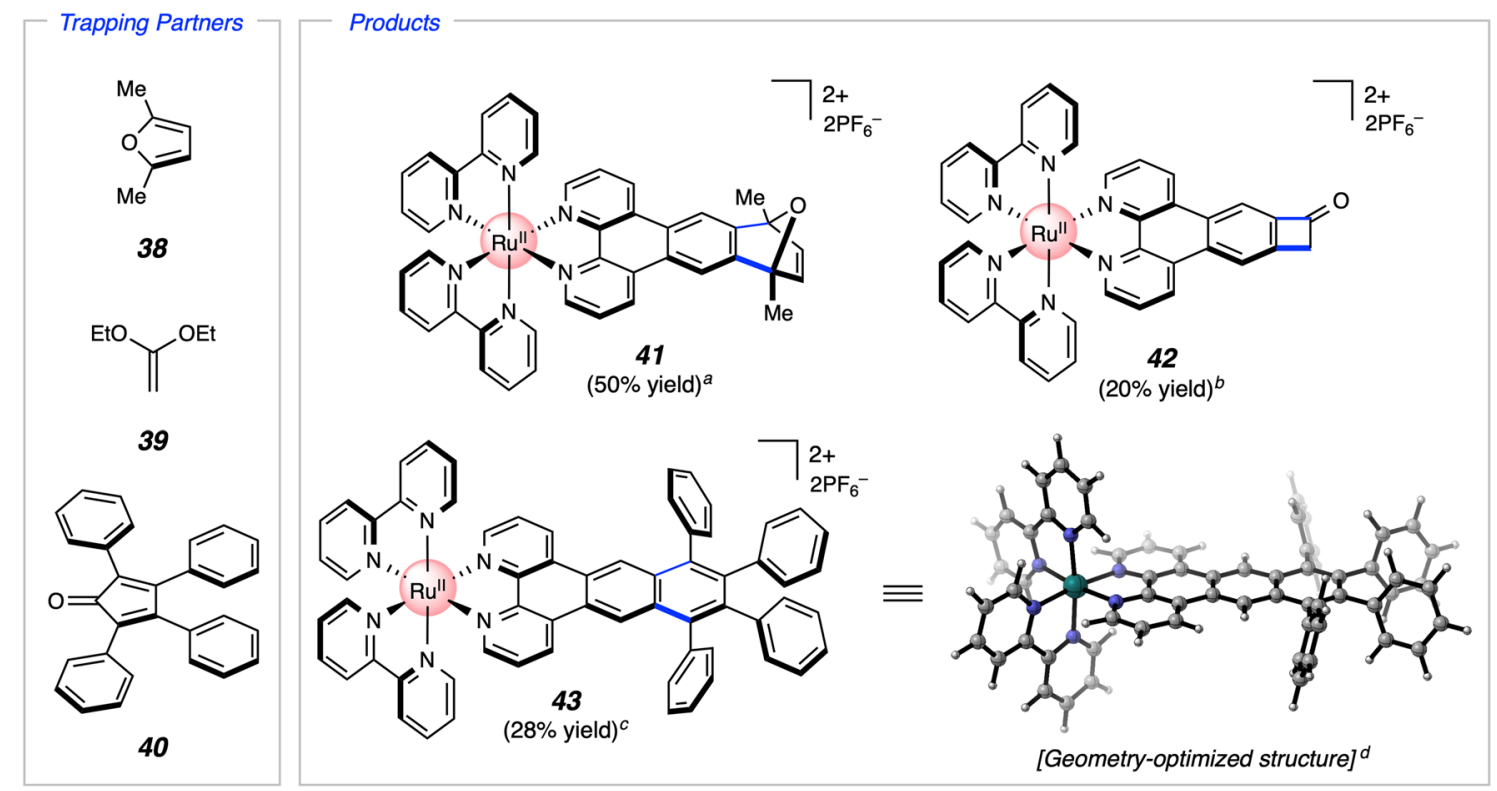

b
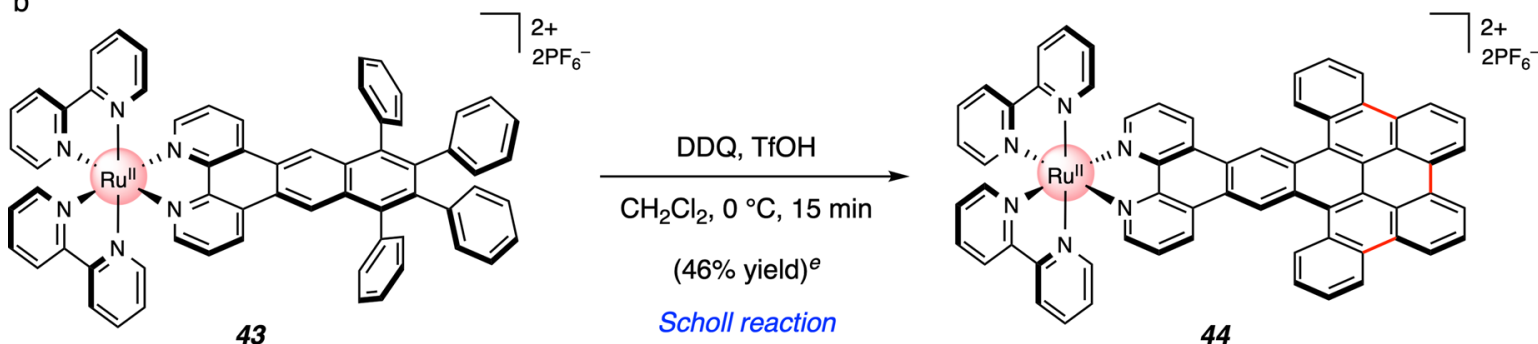

Fig. 8 Mild generation and trapping of a Ru(II) aryne. a Cycloaddition reactions of organometallic aryne 11. b Scholl reaction of $\mathbf{4 3}$ to give $\mathbf{4 4}$. aConditions: 35 ( 1 equiv), 38 (10 equiv), $\mathrm{CsF}$ (5 equiv), $\mathrm{CH}_{3} \mathrm{CN}, 23^{\circ} \mathrm{C}, 12 \mathrm{~h}$. ${ }^{\mathrm{b}} \mathrm{Conditions:} 35$ (1 equiv), 39 ( 5 equiv), $\mathrm{CsF}(3 \mathrm{equiv}), \mathrm{CH}_{3} \mathrm{CN}, 23^{\circ} \mathrm{C}, 1.5 \mathrm{~h}$; TFA. ${ }^{c}$ Conditions: 35 (1 equiv), $\mathbf{4 0}$ (2 equiv), $\mathrm{CsF}$ (5 equiv), $\mathrm{CH}_{3} \mathrm{CN}: \mathrm{CH}_{2} \mathrm{Cl}_{2}$ (2:1), $50{ }^{\circ} \mathrm{C}, 1.5 \mathrm{~h}$. ${ }^{\mathrm{d}} \mathrm{Geometry}$ optimization of $\mathbf{4 3}$ (without counterions) was performed using B3LYP/6-31 G(d)/LANL2DZ/CPCM(MeCN). e'Conditions: 43 (1 equiv), DDQ (20 equiv), $\mathrm{CH}_{2} \mathrm{Cl}_{2}: \mathrm{TfOH}(40: 1), 0{ }^{\circ} \mathrm{C}, 15 \mathrm{~min} . \mathrm{OTf}$, trifluoromethanesulfonate; Me, methyl; Et, ethyl; DDQ, 2,3-dichloro-5,6-dicyano-1,4-benzoquinone.

are oriented perpendicular to the plane of the bipyridyl ligand (see Fig. 8a and Supplementary Information). We therefore questioned whether these rings could be joined through an oxidative cyclization reaction (Fig. 8b). Gratifyingly, treatment of 43 with DDQ and triflic acid facilitated triple $\mathrm{C}-\mathrm{C}$ bond formation to give 44 in $46 \%$ yield, which notably occurs without oxidation of the $\mathrm{Ru}$ center. This approach to $\mathbf{4 4}$ circumvents solubility challenges historically encountered in efforts to access similar $\pi$-extended complexes through off-the-complex protocols ${ }^{66}$, while providing access to a unique scaffold via a Scholl reaction ${ }^{67}$ of a Ru-centered organometallic complex ${ }^{68}$.

Photophysical studies. Although our primary objective was to develop the fundamental synthetic methodology described above, we also sought to identify and evaluate trends in photophysical properties of the products obtained. We deemed this particularly important given the broad impact of $\left[\mathrm{Ru}(\mathrm{bpy})_{3}\right]^{2+}(\mathbf{1 7})$ and other polypyridyl metal complexes in light-based applications, as mentioned earlier. Thus, we compared the photophysical properties of $\left[\mathrm{Ru}(\mathrm{bpy})_{3}\right]^{2+}(\mathbf{1 7})$ to that of annulation products obtained through our methodology. Examining luminescence quantum yield and molar extinction coefficients provided useful insights and revealed adducts $\mathbf{3 1}$ and $\mathbf{3 3}$ as being particularly interesting (Fig. 9). First, a positive trend in luminescence quantum yield was observed from $\left[\mathrm{Ru}(\mathrm{bpy})_{3}\right]^{2+}(\mathbf{1 7})$ to bis(annulation) product 31 to tris(annulation) product 33. In particular, 33 exhibits a high luminescence quantum yield of $24 \%$, which is notably 2.5 -fold greater than that of $\left[\mathrm{Ru}(\mathrm{bpy})_{3}\right]^{2+}(\mathbf{1 7})$ at $9.5 \%$. A high luminescence quantum yield indicates more efficient formation of a 


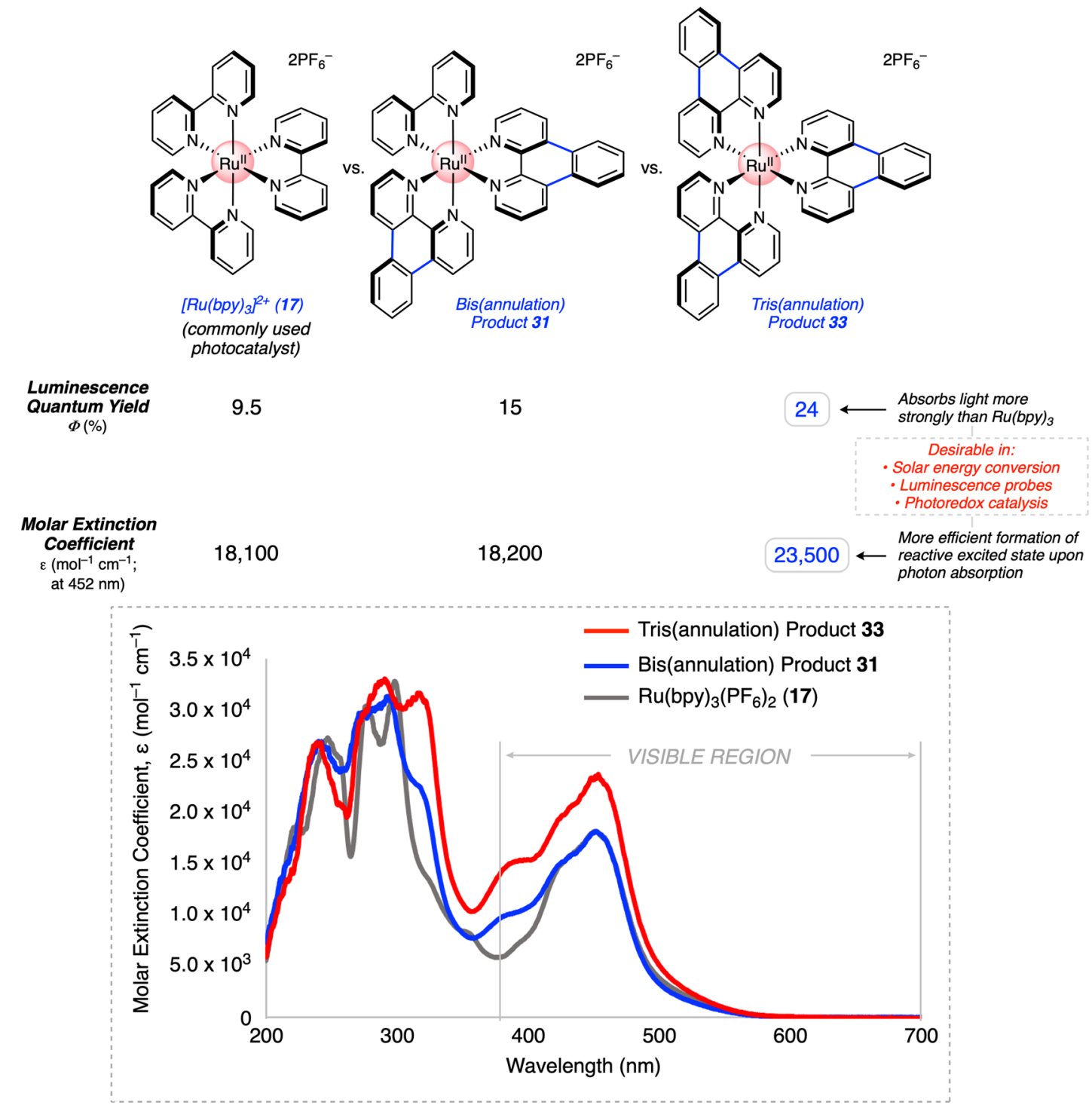

Fig. 9 Photophysical studies of bis(annulation) product 31 and tris(annulation) product 33 relative to $\left[\mathbf{R u}(\text { bpy) }]_{3}\right]^{2+}$ (17). Evaluation of luminescence quantum yield $(\Phi, \%)$ and molar extinction coefficient $\left(\varepsilon, \mathrm{mol}^{-1} \mathrm{~cm}^{-1}\right)$. Experimental absorption spectra (molar extinction coefficient) are shown from 200 to $700 \mathrm{~nm}$.

reactive excited state upon photon absorption, and is desirable in such applications as luminescence sensing, solar energy conversion, and photoredox catalysis ${ }^{36}$. Additionally, 33 displays a higher molar extinction coefficient across the visible region (e.g., $23,500 \mathrm{~mol}^{-1} \mathrm{~cm}^{-1}$ at $\left.452 \mathrm{~nm}\right)$ than that of $\left[\mathrm{Ru}(\text { bpy })_{3}\right]^{2+}(\mathbf{1 7})$ (e.g., $18,100 \mathrm{~mol}^{-1} \mathrm{~cm}^{-1}$ at $\left.452 \mathrm{~nm}\right)$, which suggests that it exhibits stronger ground state absorption of light in the visible region, a desirable quality in the aforementioned applications. All three compounds exhibit a strong visible absorption peak at $452 \mathrm{~nm}$, which is characteristic of the metal-to-ligand charge transfer (MLCT)-based luminescence that is typically observed in $\mathrm{Ru}(\mathrm{II})$ polypyridyl complexes. Of note, a shoulder also emerges in the region from 370 to $410 \mathrm{~nm}$ in compounds 31 and, more prominently, in 33 , and can likely be ascribed to delocalized ${ }^{1} \pi-\pi^{*}$ transitions that are characteristic of other $\pi$-expansive ligands (e.g., phenazine derivatives ${ }^{69}$. These findings bode well for the future use of our methodology to access complexes with promising and improved photophysical properties.

\section{Discussion}

We have developed two variants of elusive aryne on-the-complex chemistry in the context of privileged polypyridyl metal complexes. In one variant, organometallic complexes bearing aryl halides undergo transition metal-catalyzed annulations with in situ, transiently generated arynes. In the second version, an organometallic complex bearing a free aryne is intercepted in cycloaddition reactions to access complex scaffolds. Multiple $\mathrm{C}-\mathrm{C}$ bonds (i.e., up to 6) can be formed in single synthetic operations, thus providing access to metal complexes bearing unique substitution patterns. These studies not only underscore the utility of traditionally avoided aryne intermediates and the value of on-thecomplex aryne chemistry, but should also stimulate the development of on-the-complex reactions that enable transformations that are challenging by other means. Further studies will aim to evaluate and expand the utility of this methodology in accessing other valuable classes of organometallic complexes. From the standpoint of synthetic strategy, we hope these studies encourage 
the use of pre-coordinated ligands as synthons in the pursuit of complex organometallic architectures.

\section{Methods}

General procedure for Pd-catalyzed on-the-complex annulation of arynes. To a flame-dried 1-dram vial was added $\mathrm{Pd}(\mathrm{OAc})_{2}(6.7 \mu \mathrm{mol}, 10 \mathrm{~mol} \%)$, substrate 14a ( $0.066 \mathrm{mmol}, 1.0$ equiv), $\mathrm{P}(o \text {-tolyl })_{3}(6.7 \mu \mathrm{mol}, 10 \mathrm{~mol} \%), \mathrm{MeCN}(0.5 \mathrm{~mL}, 0.15 \mathrm{M})$, PhMe ( $0.5 \mathrm{~mL}, 0.15 \mathrm{M})$, silyl triflate $15(0.134 \mathrm{mmol}, 2.0$ equiv), an oven-dried magnetic stirbar, and CsF (101 mg, $0.663 \mathrm{mmol}, 10.0$ equiv) sequentially. The reaction was then purged with $\mathrm{N}_{2}$ for $5 \mathrm{~min}$ before being stirred at $110^{\circ} \mathrm{C}$ for $30-60 \mathrm{~min}$. After cooling to $23^{\circ} \mathrm{C}$, the mixture was filtered through a plug of celite with $\mathrm{MeCN}(6 \mathrm{~mL})$, concentrated under reduced pressure, and purified by flash chromatography (100\% EtOAc $\rightarrow$ 14:1:1 $\mathrm{MeCN}: \mathrm{H}_{2} \mathrm{O}$ :sat. aq. $\mathrm{KNO}_{3}$ ). To the concentrated aqueous mixture was added saturated aqueous $\mathrm{KPF}_{6}(50 \mathrm{~mL})$ to precipitate the desired product, followed by addition of $\mathrm{CH}_{2} \mathrm{Cl}_{2}(50 \mathrm{~mL})$. The layers were separated and the aqueous layer was extracted with $\mathrm{CH}_{2} \mathrm{Cl}_{2}(2 \times 50 \mathrm{~mL})$. The combined organic layers were then dried over $\mathrm{Na}_{2} \mathrm{SO}_{4}$ and concentrated under reduced pressure to afford adduct $\mathbf{1 6}$

\section{General procedure for cycloaddition reactions of Ru-centered aryne. To a} flame-dried 1-dram vial was added silyl triflate 35 ( $16.9 \mu \mathrm{mol}, 1.0$ equiv $)$ and dissolved in $\mathrm{MeCN}(0.8 \mathrm{~mL}, 0.02 \mathrm{M})$. 2,5-Dimethylfuran (38, $0.17 \mathrm{mmol}, 10$ equiv) was then added in one portion. While stirring, $\mathrm{CsF}(0.085 \mathrm{mmol}, 5$ equiv) was added in one portion and the reaction was stirred at $23^{\circ} \mathrm{C}$ for $1 \mathrm{~h}$. After $1 \mathrm{~h}$, the reaction mixture was filtered through a plug of celite with $\mathrm{MeCN}(10 \mathrm{~mL})$, concentrated under reduced pressure, and purified by flash chromatography $(100 \%$ EtOAc $\rightarrow$ 14:1:1 MeCN: $\mathrm{H}_{2} \mathrm{O}:$ sat. aq. $\mathrm{KNO}_{3}$ ). To the concentrated aqueous mixture was added saturated aqueous $\mathrm{KPF}_{6}(50 \mathrm{~mL})$ to precipitate the desired product, followed by addition of $\mathrm{CH}_{2} \mathrm{Cl}_{2}(50 \mathrm{~mL})$. The layers were separated and the aqueous layer was extracted with $\mathrm{CH}_{2} \mathrm{Cl}_{2}(2 \times 50 \mathrm{~mL})$. The combined organic layers were then dried over $\mathrm{Na}_{2} \mathrm{SO}_{4}$ and concentrated under reduced pressure to afford adduct 41

\section{Data availability}

Crystallographic data are available free of charge from the Cambridge Crystallographic Data Centre under CCDC 2048567. The authors declare that all other data supporting the findings of this study are available within the manuscript and its supplementary information files. Correspondence and requests for materials should be addressed to N.K.G. (neilgarg@chem.ucla.edu).

Received: 9 December 2020; Accepted: 25 May 2021; Published online: 17 June 2021

\section{References}

1. Noyori, R., Kitamura, M. \& Ohkuma, T. Toward efficient asymmetric hydrogenation: architectural and functional engineering of chiral molecular catalysts. Proc. Natl Acad. Sci. USA. 101, 5356-5362 (2004).

2. Monro, S. et al. Transition metal complexes and photodynamic therapy from a tumor-centered approach: challenges, opportunities, and highlights from the development of TLD1433. Chem. Rev. 119, 797-828 (2019).

3. Linck, R. C. \& Rauchfuss, T. B. In Bioorganometallics: Biomolecules, Labeling, Medicine. 403-435 (Wiley-VCH; Weinheim, 2005).

4. Braunstein, P. Functional ligands and complexes for new structures, homogeneous catalysts and nanomaterials. J. Organomet. Chem. 689 , 3953-3967 (2004).

5. Zucker, S. P., Wossidlo, F., Weber, M., Lentz, D. \& Tzschucke, C. C. Palladium-catalyzed directed halogenation of bipyridine $\mathrm{N}$-oxides. J. Org. Chem. 82, 5616-5635 (2017).

6. Soulis, K. et al. New luminescent copper(I) complexes with extended $\pi$ conjugation. Polyhedron 140, 42-50 (2018)

7. Bolger, J., Gourdon, A., Ishow, E. \& Launay, J.-P. Stepwise syntheses of monoand di-nuclear ruthenium tpphz complexes $\left[(\mathrm{bpy})_{2} \mathrm{Ru}(\mathrm{tpphz})\right]^{2-}$ and $\left[(\mathrm{bpy})_{2} \mathrm{Ru}(\mathrm{tpphz}) \mathrm{Ru}(\mathrm{bpy})_{2}\right]^{4+}\left\{\mathrm{tpphz}=\right.$ tetrapyrido[3,2-a: $2^{\prime}, 3^{\prime}-\mathrm{c}: 3^{\prime \prime}, 2^{\prime \prime}-\mathrm{h}:$ $2^{\prime \prime}, 3^{\prime \prime \prime}$-j]phenazine\}. J. Chem. Soc., Chem. Commun. 17, 1799-1800 (1995).

8. Mede, T., Jäger, M. \& Schubert, U. S. "Chemistry-on-the-complex": functional $\mathrm{Ru}^{\mathrm{II}}$ polypyridyl-type sensitizers as divergent building blocks. Chem. Soc. Rev. 47, 7577-7627 (2018).

9. Fang, Y.-Q., Polson, M. I. J. \& Hanan, G. S. Creating new binding sites in ligands and metal complexes using the Negishi cross-coupling reaction. Inorg. Chem. 42, 5-7 (2003).

10. Zedler, L. et al. Unraveling the light-activated reaction mechanism in a catalytically competent key intermediate of a multifunctional molecular catalyst for artificial photosynthesis. Angew. Chem. Int. Ed. 58, 13140-13148 (2019).
11. Anderson, S. C., Grounds, H. \& Szalóki, G. Synthesis of planar chiral ferrocenyl cyclopentadienyl chelate ligand precursors. Tetrahedron. Asymmetry 24, 1023-1034 (2013).

12. Teimuri-Mofrad, R. et al. Synthesis of new binuclear ferrocenyl compounds by hydrosilylation reactions. C. R. Chim. 20, 197-205 (2017).

13. Hiroto, S., Miyake, Y. \& Shinokubo, H. Synthesis and functionalization of porphyrins through organometallic methodologies. Chem. Rev. 117, 2910-3043 (2017).

14. Liao, K. et al. Design of catalysts for site-selective and enantioselective functionalization of non-activated primary $\mathrm{C}-\mathrm{H}$ bonds. Nat. Chem. 10, 1048-1055 (2018).

15. Fukuzawa, S., Oki, H., Hosaka, M., Sugasawa, J. \& Kikuchi, S. ClickFerrophos: new chiral ferrocenyl phosphine ligands synthesized by Click Chemistry and the use of their metal complexes as catalysts for asymmetric hydrogenation and allylic substitution. Org. Lett. 9, 5557-5560 (2007).

16. Huber, F. L., Nauroozi, D., Mengele, A. K. \& Rau, S. Synthesis and characterization of a ruthenium(II) complex for the development of supramolecular photocatalysts containing multidentate coordination spheres. Eur. J. Inorg. Chem. 2017, 4020-4027 (2017).

17. Nakamura, Y., Yoshida, S. \& Hosoya, T. Recent advances in synthetic hetaryne chemistry. Heterocycles 98, 1623-1677 (2019).

18. Pellissier, H. \& Santelli, M. The use of arynes in organic synthesis. Tetrahedron 59, 701-730 (2003)

19. Wenk, H. H., Winkler, M. \& Sander, W. One century of aryne chemistry. Angew. Chem. Int. Ed. 42, 502-528 (2003).

20. Sanz, R. Recent applications of aryne chemistry to organic synthesis. A review. Org. Prep. Proced. Int. 40, 215-291 (2008)

21. Gampe, C. M. \& Carreira, E. M. Arynes and cyclohexyne in natural product synthesis. Angew. Chem. Int. Ed. 51, 3766-3778 (2012).

22. Bhunia, A., Yetra, S. R. \& Biju, A. T. Recent advances in transition-metal-free carbon-carbon and carbon-heteroatom bond-forming reactions using arynes. Chem. Soc. Rev. 41, 3140-3152 (2012).

23. Yoshida, H. \& Takaki, K. Aryne insertion reactions into carbon-carbon $\sigma$ bonds. Synlett 23, 1725-1732 (2012).

24. Dubrovskiy, A. V., Markina, N. A. \& Larock, R. C. Use of benzynes for the synthesis of heterocycles. Org. Biomol. Chem. 11, 191-218 (2013).

25. Wu, C. \& Shi, F. A closer look at aryne chemistry: details that remain mysterious. Asian J. Org. Chem. 2, 116-125 (2013).

26. Hoffmann, R. W. \& Suzuki, K. A "hot, energized" benzyne. Angew. Chem. Int Ed. 52, 2655-2656 (2013).

27. Goetz, A. E. \& Garg, N. K. Enabling the use of heterocyclic arynes in chemical synthesis. J. Org. Chem. 79, 846-851 (2014).

28. Surry, D. S. \& Buchwald, S. L. Biaryl phosphane ligands in palladiumcatalyzed amination. Angew. Chem. Int. Ed. 47, 6338-6361 (2008).

29. Mauger, C. C. \& Mignani, G. A. An efficient and safe procedure for the largescale Pd-catalyzed hydrazonation of aromatic chlorides using Buchwald technology. Org. Process Res. Dev. 8, 1065-1071 (2004).

30. Schleth, F., Vettiger, T., Rommel, M. \& Tobler, H. Process for the preparation of pyrazole carboxylic acid amides. WO2011131544 A1 (2011).

31. Tadross, P. M. \& Stoltz, B. M. A comprehensive history of arynes in natural product total synthesis. Chem. Rev. 112, 3550-3577 (2012).

32. Wang, B., Mu, B., Chen, D., Xu, S. \& Zhou, X. Diels-Alder reactions of benzyne with indenyl iron complexes. Organometallics 23, 6225-6230 (2004).

33. Luo, S. et al. Diels-Alder reactions of benzyne with indenyl and fluorenyl ruthenium complexes. Organometallics 28, 4602-4605 (2009).

34. Grätzel, M. Dye-sensitized solar cells. J. Photochem. Photobiol., C. 4, 145-154 (2003).

35. Shaw, M. H., Twilton, J. \& MacMillan, D. W. C. Photoredox catalysis in organic chemistry. J. Org. Chem. 81, 6898-6926 (2016).

36. Arias-Rotondo, D. M. \& McCusker, J. K. The photophysics of photoredox catalysis: a roadmap for catalyst design. Chem. Soc. Rev. 45, 5804-5820 (2016).

37. Balzani, V., Bergamini, G., Marchioni, F. \& Ceroni, P. Ru(II)-bipyridine complexes in supramolecular systems, devices and machines. Coord. Chem. Rev. 250, 1254-1266 (2006)

38. McAtee, R. C., McClain, E. J. \& Stephenson, C. R. J. Illuminating photoredox catalysis. Trends Chem. 1, 111-125 (2019).

39. Gill, M. R. \& Thomas, J. A. Ruthenium(II) polypyridyl complexes and DNA-from structural probes to cellular imaging and therapeutics. Chem. Soc. Rev. 41, 3179-3192 (2012).

40. Zeglis, B., Pierre, V. C. \& Barton, J. K. Metallo-intercalators and metalloinsertors. Chem. Commun. 44, 4565-4579 (2007).

41. Song, H., Kaiser, J. T. \& Barton, J. K. Crystal structure of $\Delta-\left[\mathrm{Ru}(\mathrm{bpy})_{2} \mathrm{dppz}\right]^{2+}$ bound to mismatched DNA reveals side-by-side metalloinsertion and intercalation. Nat. Chem. 4, 615-620 (2012).

42. Keefe, M. H., Benkstein, K. D. \& Hupp, J. T. Luminescent sensor molecules based on coordinated metals: A review of recent developments. Coord. Chem. Rev. 205, 201-228 (2000). 
43. Kozhenvnikov, V. N., Deary, M. E., Mantso, T., Panayiotidis, M. I. \& Sims, M. T. Iridium(iii) complexes of 1,2,4-triazines as potential bioorthogonal reagents: metal coordination facilitates luminogenic reaction with strained cyclooctynes. Chem. Commun. 55, 14283-14286 (2019).

44. Peña, D. et al. Palladium-catalyzed cocyclization of arynes with alkynes: selective synthesis of phenanthrenes and naphthalenes. J. Am. Chem. Soc. 121, 5827-5828 (1999).

45. Yoshida, H. et al. Palladium-catalyzed bissilylation of arynes with cyclic disilanes: synthesis of benzo-annulated disilacarbocycles. J. Am. Chem. Soc. 125, 6638-6639 (2003).

46. Jeganmohan, M., Bhuvaneswari, S. \& Cheng, C.-H. A cooperative copper- and palladium-catalyzed three-component coupling of benzynes, allylic epoxides, and terminal alkynes. Angew. Chem. Int. Ed. 48, 391-394 (2009).

47. Liu, Y. et al. Palladium-catalyzed cocyclotrimerization of allenes with arynes: selective synthesis of phenanthrenes. J. Org. Chem. 74, 3199-3202 (2009).

48. Garve, L. K. B. \& Werz, D. B. Pd-catalyzed three-component coupling of terminal alkynes, arynes, and vinyl cyclopropane dicarboxylate. Org. Lett. 17, 596-599 (2015).

49. Feng, M. et al. Collective synthesis of phenanthridinone through $\mathrm{C}-\mathrm{H}$ activation involving a Pd-catalyzed aryne multicomponent reaction. Org. Lett. 18, 4352-4355 (2016).

50. Yao, T. \& He, D. Palladium-catalyzed domino Heck/aryne carbopalladation/ C-H functionalization: synthesis of heterocycle-fused 9,10 dihydrophenanthrenes. Org. Lett. 19, 842-845 (2017).

51. Pozo, I. et al. Synthesis of nanographenes, starphenes, and sterically congested polyarenes by aryne cyclotrimerization. Acc. Chem. Res. 52, 2472-2481 (2019).

52. Liu, Z., Zhang, X. \& Larock, R. C. Synthesis of fused polycyclic aromatics by palladium-catalyzed annulation of arynes using 2-halobiaryls. J. Am. Chem. Soc. 127, 15716-15717 (2005).

53. Liu, Z. \& Larock, R. C. Highly efficient route to fused polycyclic aromatics via palladium-catalyzed aryne annulation by aryl halides. J. Org. Chem. 72, 223-232 (2007).

54. Iranmanesh, H. et al. Chiral ruthenium(II) complexes as supramolecular building blocks for heterometallic self-assembly. Inorg. Chem. 55, 12737-12751 (2016).

55. Bennett, M. A. \& Schwemlein, H. P. Metal complexes of small cycloalkynes and arynes. Angew. Chem. Int. Ed. Engl. 28, 1296-1320 (1989).

56. Verhoeven, J. W. et al. Complex comprising a rare-earth metal ion and a complexing moiety. EP1019401 B1 (1998).

57. Lu, W., Vicic, D. A. \& Barton, J. K. Reductive and oxidative DNA damage by photoactive platinum(II) intercalators. Inorg. Chem. 44, 7970-7980 (2005).

58. Geri, J. B. et al. Microenvironment mapping via Dexter energy transfer on immune cells. Science 367, 1091-1097 (2020).

59. Colombo, M. G., Hauser, A. \& Guedel, H. U. Evidence for strong mixing between the LC and MLCT excited states in bis(2-phenylpyridinato-C2,N') (2,2'-bipyridine)iridium(III). Inorg. Chem. 32, 3088-3092 (1993).

60. Wang, C., deKrafft, K. E. \& Lin, W. Pt nanoparticles@photoactive metal-organic frameworks: efficient hydrogen evolution via synergistic photoexcitation and electron injection. J. Am. Chem. Soc. 134, 7211-7214 (2012).

61. Bolink, H. J. et al. Long-living light-emitting electrochemical cells - control through supramolecular interactions. Adv. Mater. 20, 3910-3913 (2008).

62. $\mathrm{Li}, \mathrm{Y}$. et al. Effects of extended $\pi$-conjugation in phenanthroline $\left(\mathrm{N}^{\wedge} \mathrm{N}\right)$ and phenylpyridine $\left(\mathrm{C}^{\wedge} \mathrm{N}\right)$ ligands on the photophysics and reverse saturable absorption of cationic heteroleptic iridium(III) complexes. J. Phys. Chem. C. 118, 6372-6384 (2014)

63. Werner, G., Lehmann, C. W. \& Butenschön, H. The first anionic thia-Fries rearrangements at ferrocene: ready access to trifluoromethylsulfonylsubstituted hydroxyferrocenes and an extremely high interannular stereoinduction between cyclopentadienyl ligands. Adv. Synth. Catal. 352, 1345-1355 (2010).

64. Duong, H. M. et al. Efficient synthesis of a novel, twisted and stable, electroluminescent "twistacene." Org. Lett. 5, 4433-4436 (2003).
65. Suzuki, S., Itami, K. \& Yamaguchi, J. Synthesis of octaaryl naphthalenes and anthracenes with different substituents. Angew. Chem. Int. Ed. 56, 15010-15013 (2017).

66. Graczyk, A. et al. Terpyridine-fused polyaromatic hydrocarbons generated via cyclodehydrogenation and used as ligands in $\mathrm{Ru}(\mathrm{II})$ complexes. Dalton Trans. 41, 7746-7754 (2012).

67. Grzybowski, M. et al. Synthetic applications of oxidative aromatic couplingfrom biphenols to nanographenes. Angew. Chem. Int. Ed. 59, 2998-3027 (2020).

68. Draper, S. M. et al. Complexed nitrogen heterosuperbenzene: the coordinating properties of a remarkable ligand. J. Am. Chem. Soc. 126, 8694-8701 (2004).

69. Reichardt, C. et al. Predictive strength of photophysical measurements for in vitro photobiological activity in a series of $\mathrm{Ru}(\mathrm{II})$ polypyridyl complexes derived from $\pi$-extended ligands. Inorg. Chem. 58, 3156-3166 (2019).

\section{Acknowledgements}

The authors are grateful to the University of California, Los Angeles for financial support. We are grateful to the NIH-NIGMS (R01 GM123299 and R35 GM139593 for N.K.G.), the Foote Family (J.V.C.), and the Trueblood Family (for N.K.G.). These studies were supported by shared instrumentation grants from the NSF (CHE-1048804) and the NIH NCRR (S10RR025631).

\section{Author contributions}

J.V.C., K.A.S., and R.B.S. designed and performed experiments and analyzed experimental data. N.K.G. directed the investigations and prepared the manuscript with contributions from all authors; all authors contributed to discussions. The authors acknowledge Dr. Evan Darzi (UCLA) for insightful discussions and Vince Hipwell (UCLA) for experimental assistance.

\section{Competing interests}

The authors declare no competing interests.

\section{Additional information}

Supplementary information The online version contains supplementary material available at https://doi.org/10.1038/s41467-021-23970-8.

Correspondence and requests for materials should be addressed to N.K.G.

Peer review information Nature Communications thanks Pier Giorgio Cozzi, Sven Rau and the other, anonymous, reviewer(s) for their contribution to the peer review of this work

Reprints and permission information is available at http://www.nature.com/reprints

Publisher's note Springer Nature remains neutral with regard to jurisdictional claims in published maps and institutional affiliations.

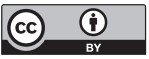

Open Access This article is licensed under a Creative Commons Attribution 4.0 International License, which permits use, sharing, adaptation, distribution and reproduction in any medium or format, as long as you give appropriate credit to the original author(s) and the source, provide a link to the Creative Commons license, and indicate if changes were made. The images or other third party material in this article are included in the article's Creative Commons license, unless indicated otherwise in a credit line to the material. If material is not included in the article's Creative Commons license and your intended use is not permitted by statutory regulation or exceeds the permitted use, you will need to obtain permission directly from the copyright holder. To view a copy of this license, visit http://creativecommons.org/ licenses/by/4.0/.

(C) The Author(s) 2021 